\title{
MASTER
}

ANL-77-82

\section{COMPUTATION OF THE WEIGHT FUNCTION FROM A STRESS INTENSITY FACTOR}

\author{
by
}

H. J. Petroski and J. D. Achenbach

\section{BASE TECHIVOLOGY}

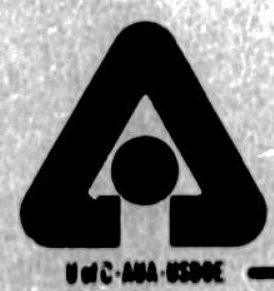

ARGONNE NATIONAL LABORATORY, ARGONNE, ILLINOIS Propared for the U. S. DEPARTMENT OF ENERGY under Contract W-31-100-Eng-38 

A. $11-77-4:$

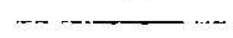

ARG OONE NATIUNAL LABOREIORY

$9700 \mathrm{~S}$ ith Cass Avrum.

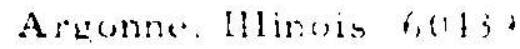

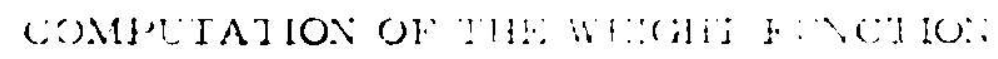

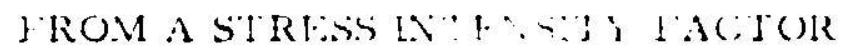

$\vdots \therefore$

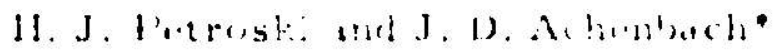

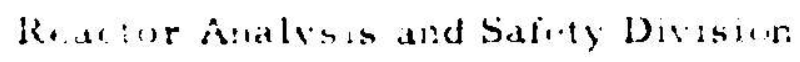

Octuber 1977

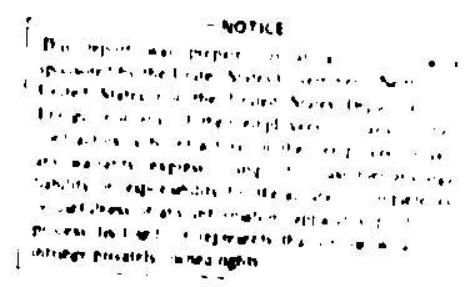

-Dept. of Civil Engincering, Northwistern Unıversity. 

TABLE OF CONTENTS

Page

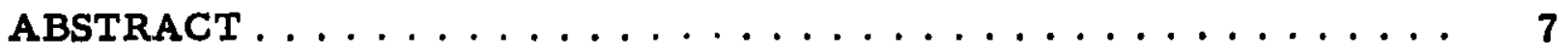

I. INTRODUCTION. ..................

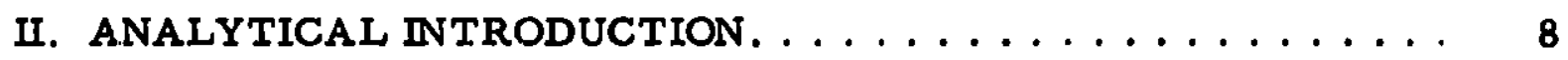

III. MIODE-I CRACK-FACE DISPLACEMENTS $\ldots \ldots \ldots \ldots 10$

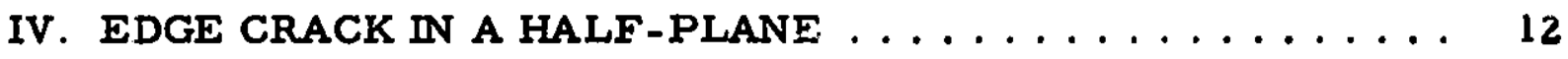

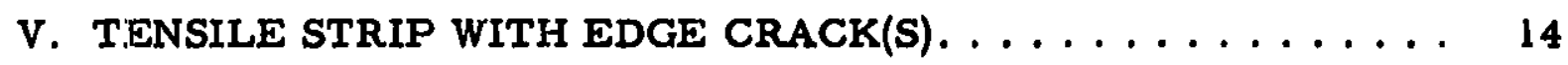

vi. RADIAL CRACK FROM A CIRCULAR HOLE . . . . . . . . 16

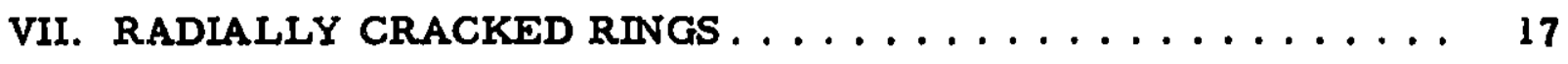

vill. CORNER-CRACKED HEXCAN .............. 19

IX. CONCLUSIONS. ..................... 23

ACKNOWLEDGMENTS $\ldots \ldots \ldots \ldots \ldots \ldots \ldots \ldots \ldots \ldots \ldots$

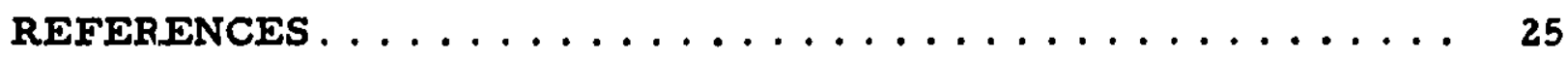




\section{LIS'S OF FIGURES}

No.

Title

$\underline{\text { Page }}$

1. Edge Crack in a Half-space . . . . . . . . . . . .

2. Comparison of Weight-function Results with Handboc : Values of the Function $\mathrm{H}(\mathrm{b} / \mathrm{a}) \ldots \ldots \ldots \ldots \ldots \ldots \ldots$

3. Tensile Strips with Edge Cracks: (a) Symmetric Cas z; (b) Asym-

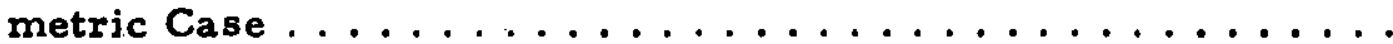

4. Crack-opening Displacements Computed from Two-term Representation Compared with Results of Keer and Freedman's Analysis for the Symmetric Case . . . . . . . . . . .

5. Crack-opening Displacements Computed from Two-term Representation Compared with Results of Keer and Freedman's Analysis for the Asymmetric Case . . . . . . . . . . . . .

6. Stress-intensity-factor Calibrations for a Radial Crack Emanating from a Circular Hole. . . . . . . . . . . . . . . .

7. Stress-intensity-factor Calibrations for Radially Cracked Ring s Subject to Uniform Crack-face Pressure (after Grandt) . . . . . .

8. Comparison of Stress-intensity-factor Calibrations for Radially Cracked Rings under External Tension . . . . . . . . . .

9. Comparison of Stress-intensity-factor Calibrations for Radially Cracked Rings Compressed by Cox.centrated Forces ........ 19

10. Cracks in a Hexcan Section . . . . . . . . . . . . 20

11. Dimensions of Hexcan Considered. . . . . . . . . . . . 20

12. Stress Intensity Factors for a Uniformly Pressurized Hexcan with a Corner Crack. . . . . . . . . . . . . . . .

13. Comparison of Stress-intensity-factor Calibrations for a Cornercracked Hexcan Loaded at Opposite Midflats. . . . . . . . . 


\section{LIST OF TABLES}

No.

Title

$\underline{\text { Page }}$

I. Dimensionless Displacement $\mu \mathrm{u}(\mathrm{a}, 0) /\left[\sigma_{0}(1-v)\right]$ at Crack Mouth for Strip with Edge $\operatorname{Crack}(s) ; \mu=$ Shear Modulus. . . . . . . . . .

II. Dimensionless Displacement $\mu \mathrm{u}(\mathbf{a}, \mathbf{x}) /\left[\sigma_{0}(1-v)\right]$ for Various Values of $x / a$ and $a / \pi$ for a Strip with Edge $\operatorname{Crack}(s) ; \mu=$ Shear

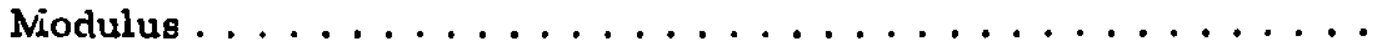

III. Values of the Functions $F$ and $G$ for the Corner-cracked Hexcan Subject to Uniform Pressure . . . . . . . . . . . . . . . 21

IV. Polynomial Coefficients for Representations of the Functions $F$

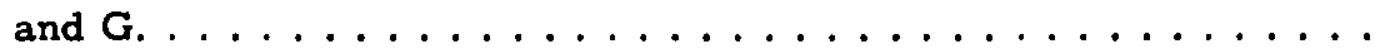


COMPUTATION OF THE WEIGHT FUNCTION

FROM A STRESS INTENSITY FAC'TOR

by

H. J. Petroski and J. D. Achenbach

\title{
ABSTRACT
}

\begin{abstract}
A simple representation for the crack-face displacement is used to compute a weight function solely from stress intensity factor $s$ for a reference loading configuration. Crackface displacements given by the representation are shown to be in good agreement with analytical results for cracked tensile strips, and stress intensity factors computed from the weight function agree well with those for edge cracks in half-planes, radial cracks from circular holes, and radially cracked rings. The technique involves only simple quadrature, and its efficacy is demonstrated by the exarnple computations.
\end{abstract}

The weight function for a corner crack in an LMFBR hexagonal subassembly duct is constructed from stress-intensityfactor results for the uniformly overpressurized case, and it is shown how this may be used to determine the stress intensity factors for other loading cases.

\section{INTRODUCTION}

Standard solutions are not available for problems involving the stress analysis of cracks in the unique geometry of the hexagonal ducts of LMFBR designs. Yet the highly stressed corners of these hexcans, where cracks may be present, are areas of special interest for fracture-mechanics studies for fastreactor analysis and safety.

After prolonged exposure to the fast-neutron environment in a reactor core, there is a loss of ductility of the stainless steel of which the hexcans are made, and there is an increased possibility that any cracks or flaws that might exist in the hexcan wall cc'lld become unstable and cause the duct to fracture under accident loading. Toward end of life, linear elastic fracture mechanics is expected to apply to cracks in hexcans, and in this theory the eeverity of a crack is measured by its stress intensity factor. When this factor reaches a critical value, known as the fracture toughness of the material, a crack can propagate in a brittle manner. 
For cracks in the midflat region of a hexcan wall, handbook calibrations oi stress intensity factors for cracks in beams subject to tension and bending are applicable. In the sharp corner region of the hexcan, however, there is no such easy means of determining stress intensity factors.

Finite-element techniques are available, but these become costly and time-consuming when one wishes to conduct parametric studies in fracture mechanics. Therefore, alternative techniques have been explored, and a weight-function technique has been found to be especially simple and accurate. This technique has the added attraction that, in principle, a similar technique may be extended to dynamic, plastic, and three-dimensional prcblems.

\section{ANALYTICAL INTRODUCTION}

For two-dimensional problems it has been shown ${ }^{1,2}$ that if the crackface displacement $u(a, x)$ and the Mode-I stress intensity factor $K$ are known for a symmetrical load system on a linearly elastic body containing a crack of length $a$, then the stress intensity factor $K^{(2)}$ for any other symmetrical load system on that same body may be obtained from

$$
K^{(2)}=\int_{0}^{a} \sigma(x) h(a, x) d x,
$$

where $h(a, x)$ is a weight function, defined as

$$
h(a, x)=H \frac{\partial u}{\partial a} / K .
$$

In Eq. 1, the integration is carried out over the length a of the crack, $H$ is a material constant, and $\sigma(x)$ is the stress distribution across the plane of the crack in the unflawed body loaded by the force system with which $\mathrm{K}^{(2)}$ is associated. The principle of superposition of linear elasticity implies that, for purposes of calculating stres s intensity factors, loading the crack faces with $o(x)$ is equivalent to loading the cracked body with loads that give rise to $o(x)$ in the absence of a crack.

Equation 1 has been used successfully to calculate stress intensity factors for a number of practical applications. Grandt ${ }^{3}{ }^{4}$ has used Eq. 1 to calculate plane-strain stress intensity factors for a variety of problems involving cracked rings and cracked fastener holes. The advantage of Eq. 1 is that, once the stress intensity factor and crack-face displacement are established for a reference problem, the stress intensity factor for any other symmetric loading of that body follows by a simple quadrature. Essentially, the reference problem provides enough information to enable one to calculate the weight function for the body. 
Although the evaluation of the integral in Eq. 1 is straightforward, even when a numerical quadrature is required, applications of this formula frequently require preliminary work to establish the appropriate values of the derivative $\partial \mathrm{u} / \mathrm{Oa}$ that appears in the weight function. This has been found necessary because the analytical solutions for $K$ that are available for use as the data for the reference weight function in Eq. 1 are often unaccompanied by displacement data from which to construct the coinplete weight function. Thus, in Grandt's analysis ${ }^{3}$ of through-cracked fastener holes, he found it necessary to supplement Bowie's results ${ }^{5}$ for a radially cracked hole with a finiteelement analysis in order to establish the corresponding crack-mouth opening displacement.

The entire crack-face displacement need not be known if one assumes, as Grandt ${ }^{3} \mathrm{did}$, a one-parameter form for the crack shape. In Grandt's analysis of cracked rings, ${ }^{4}$ his reference solution was provided by Jones' results ${ }^{6}$ for cylindrical fracture toughness specimens, which included both crack-mouth opening displacements and stress intensity factors as functions of crack length.

Here we show how calibrations of the stress intensity factor for a reference problem provide enough information by themselves to calculate approximate stress intensity factors associated with all other symmetric loading conditions of the same body. This simplification follows from the observation that an integral identity results if one uses Eq. 1 to calculate the stress intensity factor associated with the reference problem itself. Then, if a reasonable one-parameter form for the crack displacement is assumed, the parameter may be determined from the integral identity. This information can subsequently be used to derive the weight function for the body. Stress intensity factors for other than the reference loading then follow as before from Eq. 1 . Results obtained with the aid of the simple representation for the crack-opening shape agree well with existing results for stress intensity factors, though some caution should be exercised for extremely deep cracks.

The expression Grandt ${ }^{3,4}$ uses for the crack opening is a conic-section representation due to Orange." Although our approach may be used to compute the conic-section coefficient, the complicated way in which this coefficient appears in Orange's representation makes it desirable to derive an alternative representation as shown in this report.

In the next section, we consider a representation for the crack-face displacement in terms of one unknown function of the crack length $a$, and we derive a simple expression for this function. To illustrate the results, we conmider the edge crack in a half-plane with concentrated loads on the crack faces. Next we consider the strip with one or two edge cracks, and we compare the crack-face displacements computed by Keer and Freedman ${ }^{8}$ with displacements obtained in this report. Finally, we demonstrate the ability of our displacement representation to determine strese intensity factors for a variety of loading 
once a reference $K$ has been used to fix the form of $u(a, x)$. As an example, we compute stress intensity factors for a radial crack at the circumference of a circular hole in a body under biaxial loading. The results agree well with those obtained by Grandt. ${ }^{3}$ Stress intensity factors are also computed for a cracked ring under a variety of loading conditions. The results are in excellent agreement with thọse obtained in Ref. 4.

With the above verification of the weight-function technique, we are able to apply it confidently to problems for which calibrations for stress intensity factors do not exist. The problem of a hexcan with a corner crack is one such problem. By employing a calibration for the stress intensity factor for cracked hexcans subject to uniform overpressure, the weight function for a cornercracked hexcan is derived and applied to the problem of determining the calibration of the stress intensity factor for a hexcan loaded nonuniformly by concentrated loads at two opposite midflats.

\section{MODE-I CRACK-FACE DISPLACEMENTS}

One obstacle to the direct use of Eq. 1 is that the solutions for the stress intensity factor that are available in the literature to serve as reference data are often not accompanied by data for crack-face displacements. To overcome this obstacle, a simple method has been developed in this report to approximate $u(a, x)$ solely on the basis of knowledge of the associated stress intensity factor. The method is based on the observation that Eq. 1 must reduce to an identity if the stress distribution $\sigma(x)$ is taken to be exactly that of the reference problem for which $K$ is known. Then $K^{(2)}=K$, and Eq. 1 becomes

$$
K^{2}=H \int_{0}^{a} O(x) \frac{\partial u}{\partial a} d x .
$$

When $K, H$, and $\sigma(x)$ are known, Eq. 3 provides information about $u(a, x)$ independently of further analysis of the reference problem.

Since $u(a, x)=0$ at $x=a$, the derivative with respect to a may be brought outside of the integral. Subsequent integration with respect to a yields

$$
\int_{0}^{a}[K(a)]^{2} d a=H \int_{0}^{a} \sigma(x) u(a, x) d x .
$$

It is of interest to check Eq. 3 for a crack of length $a$ in an infinite body subjected to a remote uniform tensile stress $\sigma_{0}$. If the origin of the $x y$ coordinate aystem is at one tip of the crack, we have

$$
u(a, x)=: 2 \sigma_{0} x^{1 / 2}(a-x)^{1 / 2} / H ; K=\sigma_{0}(\pi a / 2)^{1 / 2} .
$$


Here $u(a, x)$ is the displacement along the upper surface of the crack, and

$$
\mathbf{H}=\mathbf{E} /\left(1-\nu^{2}\right)
$$

for plane strain. Substitution of Eqs. 5a,b in Eq. 4 verifies the identity.

Although Eq. 4 is an integral equation, it cannot be solved rigorously for $u(a, x)$, since the functional dependence of $u$ on both $a$ and $x$ is unknown. Thus, Eq. 4 must be supplemented by a judiciously selected representation for $u(a, x)$, in which the functional dependence of $u(a, x)$ on one of the variables, say $x$, is assumed a priori. Our choice of a representation for $u$ is directed by three criteria: (1) The representation must possess the proper limiting behavior near the crack tip, (2) it must demonstrate consistent behavior for small cracks, and (3) it raust L" simple enough so that unknown parameters can be easily determined from a knowledge of $K$ and $\sigma$ alone. The representations we consider in this repic are particularly suited for edge cracks.

It is well known ${ }^{9}$ that, in the vicinity of any crack tip,

$$
u(a, x)=\frac{4 K}{H}\left(\frac{a-x}{2 \pi}\right)^{1 / 2}
$$

where $x$ is measured from the crack mouth and $x=a$ is the crack tip. The constant $\mathrm{H}$ is defined by Eq. 6 for plane-strain conditions. For edge cracks, $\mathrm{K}$ generally can be conveniently expressed in the form

$$
K=\sigma_{0} F(a / L)(\pi a)^{1 / 2}
$$

where $\sigma_{0}$ and $L$ are characteristic stress and length parameters. In our representation, we take Eq. 7 as the first term, while subsequent terms are of higher order in $(a-x)$, so that criterion (1) is satisfied. The choice of subsequent terms is largely a matter of judgement, the limitation being that only one unknown function can be determined from Eq. 4. Here we elect to take the second term in an expansion around the crack tip, i.e., a term of the general form $f(a)(a-x)^{3 / 2}$.

To satisfy Eq. 4 in the limit $a \rightarrow 0$ and thus to satisfy criterion (2), we must have $f(a)=0\left(1 / a^{1 / 2}\right)$ as $a \rightarrow 0$. On the basis of these considerations, we assume the following displacement representation:

$$
u(a, x)=\frac{\sigma_{0}}{H \sqrt{2}}\left[4 F\left(\frac{a}{L}\right) a^{1 / 2}(a-x)^{1 / 2}+G\left(\frac{a}{L}\right) a^{-1 / 2}(a-x)^{3 / 2}\right]
$$

Here $F(a / L)$ is known, while $G(a / L)$ is to be determined from Eq. 4. We note that the second term in Eq. 9 is not merely the second term in a Williams-type expansion, ${ }^{16}$ but rather is a representation for all higher-order terms. Although 
other representations could be equally suitable, Eq. 9 has the advantage that it may be completely specified by simple and explicit quadratures, thus satisfying criterion (3). It presents a distinct calculational advantage over representations such as Orange's conic section, ${ }^{7}$ whose specification through the identity given by Eq. 4 would involve the solution of an integral equation. Moreover, Eq. 9 gives good results, as will be shown in examples in subsequent sections.

After substitution of Eq. 9 in Eq. 4, we can solve for $G(a / L)$ as

$$
G(a / L)=\left[I_{1}(a)-4 F(a / L) a^{1 / 2} I_{2}(a)\right] a^{1 / 2} / I_{3}(a),
$$

where

$$
\begin{aligned}
& I_{1}(a)=\pi \sigma_{0} \sqrt{2} \int_{0}^{a}[F(a / L)]^{2} a d a, \\
& I_{2}(a)=\int_{0}^{a} \sigma(x)(a-x)^{1 / 2} d x,
\end{aligned}
$$

and

$$
I_{3}(a)=\int_{0}^{a} \sigma(x)(a-x)^{3 / 2} d x .
$$

Equations 12 and 13 are, of course, particularly simple if the stress distribution for the reference problem is uniform, i.e., $\sigma(x)=\sigma_{0}$. Once $G(a / L)$ has been determined, $\partial u / \partial a$ and $h(a, x)$ can be determined from Eqs. 9 and 2, respectively, and stress intensity factors for other loading conditions can subsequently be computed from Eq. 1 .

For small cracks $(a \rightarrow 0)$, the integrals in Eqs. $11-13$ may be evaluated in closed form after applying the mean value theorem. Then the limiting value of $G$ may be determined as

$$
G(0)=\left[\frac{5 \pi \sqrt{2}}{4} \frac{\sigma_{0} F(0)}{\sigma(0)}-\frac{20}{3}\right] F(0) .
$$

When the cheracteristic atress $\sigma_{0}$ is taken to be the crack-mouth pressure loading $\sigma(0), F(0)=1.1215$ and $G(0)=-0.4916$.

\section{EDGE CRACK IN A HALF-PLANE}

As a simple illustration, we coneider an edge crack in a half-plane, whose faces are subjected to various pressure distributions. For the reference 
problem, we take the case of uniform remote tension of magnitude $\sigma_{0}$, which for $K$ calculations is equivalent to uniform crack-face pressure (see Fig. 1a). For that case,

$$
K=1.1215 \sigma_{0}(\pi a)^{1 / 2} \text {, i.e., } F(a / L)=1.1215 \text {. }
$$

Substituting in Eq. 10, we obtain

$$
G(a / L)=-0.4916 \text {. }
$$

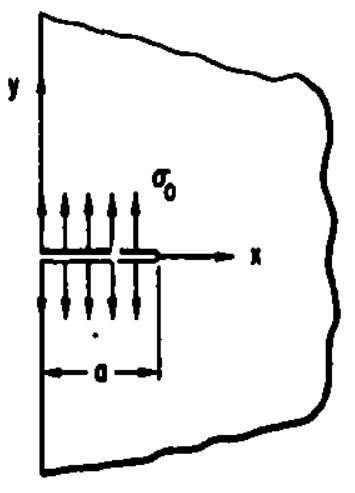

(0)

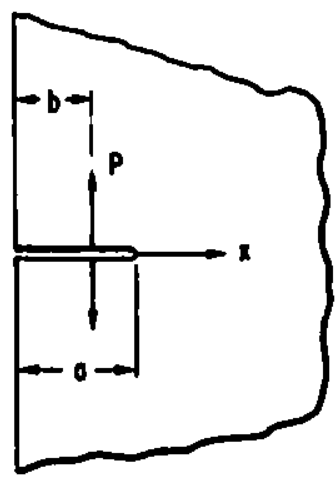

(b)
Fig. 1

Edge Crack in a Half-space

Let us now use this result to compute the stress intensity factor for concentrated normal loads applied at the crack faces as shown in Fig. Ib. For that case,

$$
\sigma(x)=P \delta(x-b) .
$$

Equation 1 then yields

$$
\mathbf{K}^{(2)}=\frac{2 P}{(\pi a)^{1 / 2}} \frac{H(b / a)}{\left[1-(b / a)^{2}\right]^{1 / 2}},
$$

where

$$
H\left(\frac{b}{a}\right)=\left[0.7071\left(2-\frac{b}{a}\right)-0.0775\left(1-\frac{b}{a}\right)\left(2+\frac{b}{a}\right)\right]\left(1+\frac{b}{a}\right)^{1 / 2} .
$$

For $b=0$,

$$
K^{(2)}=1.2592 \frac{2 P}{(\pi a)^{1 / 2}} .
$$

In Ref. 10 (p. 8.2), the stress intensity factor for this problem is given with a numerical factor of 1.3 rather then 1.2592 , which would imply an exror of about 3\%. Figure 2 comperes H(b/a) with the result of Ref. 10 (p. 8.3). 


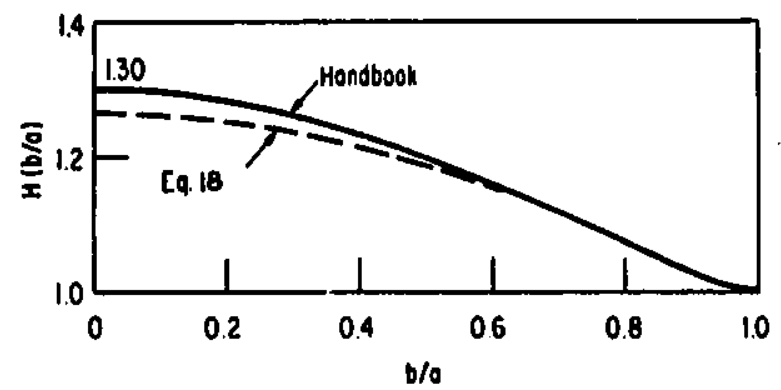

Fig. 2

Comparison of Weight-function Results with Handbook Values of the Function $\mathrm{H}(\mathrm{b} / \mathrm{a})$

The solution to the concentrated-load problem can be used as a Green's function to compute the stress intensity factor for an arbitrary distribution of crack-face pressures. Since the largest error, which is at $b=0$, is only about $3 \%$, a distributed pressure would give a still smisller error.

\section{TENSILE STRIP WITH EDGE CRACK(S)}

Keer and Freedman ${ }^{8}$ have used a combined series and integral-transform technique to obtain both stress intensity factors and crack-face displacements for a cracked tensile strip. The geometries they have considered are shown in Fig. 3. Their crack-face displacements can be used for comparison with the displacements computed by the method of this report.

The dimensionless stress intensity factors reported in Ref. 8 were fitted with a fifth-degree polynomial, and the crackface displacements $u(a, x)$ were determined from Eq. 9, where $G(a / \pi)$ was computed from Eq. 10. Here it should be noted that a $\pi$ length unit was the characteristic width parameter in Ref. 8. The computations are simple. The crack-face displacements at the mouth of the crack, which follow from Eq. 9 for $x=0$, are tabulated in Table I, where we have also listed the corresponding results from Table 1 of Ref. 8 . We note that the agreement is satisfactory, except for the symmetric problem when values of $a / \pi$ are close to unity, i.e., when the two edge cracks run almost through the entire width of the strip. A maximum difference of $5 \%$ is maintained for cracks up to $70 \%$ of the strip width in the symmetric case, and up to $80 \%$ in the $28 \mathrm{ym}$ metric case. In general, Eq. 9 gives smaller crack-face displacements than the results of Ref. 8.

For a number of specific a/ $\pi$ values we have listed crack face displacements for various values of $x / a$ in Table II. In this Table we have also listed results which 
were obtained from Figs. 3 and 4 of Ref. 8. Again the agreement is very satisfactory, as illustrated graphically in our Figs. 4 and 5 . We note that it is not the absolute value of the crack-face displacement that is used in the weight-function technique, but the derivative $\partial u / \partial a$, so that calculations of the stress intensity factor may be expected to be in even better agreement with analytical results.

TA.BLE I. Dimensionless Displacement $\mu u(a, 0) /\left[\sigma_{0}(1-v)\right]$ at

Crack Mouth for Strip with Edge Crack(s); $\mu=$ Shear Modulus

\begin{tabular}{lccccc}
\hline & \multicolumn{2}{c}{ Symmetric } & Problem & & \multicolumn{2}{c}{ Asymmetric Problem } \\
\cline { 6 - 6 } a $/ \pi$ & Eq. 9 & Ref. 8 & & Eq.9 & Ref. 8 \\
\hline 0.05 & 0.222 & 0.229 & & 0.226 & 0.233 \\
0.10 & 0.441 & 0.456 & & 0.473 & 0.488 \\
0.15 & 0.659 & 0.681 & 0.763 & 0.786 \\
0.20 & 0.875 & 0.904 & 1.119 & 1.152 \\
0.30 & 1.305 & 1.349 & 2.171 & 2.218 \\
0.40 & 1.740 & 1.802 & 4.064 & 4.115 \\
0.50 & 2.201 & 2.282 & 7.805 & 7.795 \\
0.60 & 2.708 & 2.818 & 15.947 & 15.717 \\
0.65 & - & - & 23.78 & 23.209 \\
0.70 & 3.311 & 3.450 & - & - \\
0.80 & 4.057 & 4.318 & 103.233 & 102.11 \\
0.85 & - & - & 246.44 & 225.54 \\
0.90 & 5.133 & 5.734 & - & - \\
0.95 & 5.588 & 7.129 & - & - \\
0.975 & 5.274 & 8.519 & - & - \\
\hline
\end{tabular}

TABLE II. Dimensionless Displacement $\mu u(a, x) /\left[\sigma_{0}(1-v)\right]$ for Various Values of $x / a$ and $a / \pi$ for a Strip with Edge Crack(s); $\mu$ = Shear Modulus

\begin{tabular}{|c|c|c|c|c|c|c|c|}
\hline \multirow[b]{2}{*}{$\mathbf{x} / \mathbf{a}$} & \multirow[b]{2}{*}{$a / \pi$} & \multicolumn{3}{|c|}{ Symmetric Problem } & \multicolumn{3}{|c|}{ Asymmetric Problem } \\
\hline & & 0.1 & 0.5 & 0.8 & 0.1 & 0.5 & 0.85 \\
\hline 0.8 & $\begin{array}{l}\text { Eq. } 9 \\
\text { Ref. } 8\end{array}$ & $\begin{array}{l}0.217 \\
0.210\end{array}$ & $\begin{array}{l}1.126 \\
1.103\end{array}$ & $\begin{array}{l}2.364 \\
2.313\end{array}$ & $\begin{array}{l}0.231 \\
0.222\end{array}$ & $\begin{array}{l}2.944 \\
2.865\end{array}$ & $\begin{array}{l}54.8 \\
54.8\end{array}$ \\
\hline 0.6 & $\begin{array}{l}\text { Eq. } 9 \\
\text { Ref. } 8\end{array}$ & $\begin{array}{l}0.300 \\
0.295\end{array}$ & $\begin{array}{l}1.542 \\
1.516\end{array}$ & $\begin{array}{l}3.149 \\
3.088\end{array}$ & $\begin{array}{l}0.320 \\
0.317\end{array}$ & $\begin{array}{l}4.357 \\
4.385\end{array}$ & $\begin{array}{l}97.1 \\
98.5\end{array}$ \\
\hline 0.4 & $\begin{array}{l}\text { Eq. } 9 \\
\text { Ref. } 8\end{array}$ & $\begin{array}{l}0.359 \\
0.357\end{array}$ & $\begin{array}{l}1.827 \\
1.819\end{array}$ & $\begin{array}{l}3.619 \\
3.601\end{array}$ & $\begin{array}{l}0.383 \\
0.380\end{array}$ & $\begin{array}{l}5.573 \\
5.608\end{array}$ & $\begin{array}{l}142.9 \\
140.6\end{array}$ \\
\hline 0.2 & $\begin{array}{l}\text { Eq. } 9 \\
\text { Ref. } 8\end{array}$ & $\begin{array}{l}0.405 \\
0.409\end{array}$ & $\begin{array}{l}2.039 \\
2.064\end{array}$ & $\begin{array}{l}3.904 \\
3.986\end{array}$ & $\begin{array}{l}0.432 \\
0.437\end{array}$ & $\begin{array}{l}6.708 \\
6.721\end{array}$ & $\begin{array}{l}192.7 \\
183.6\end{array}$ \\
\hline 0.0 & $\begin{array}{l}\text { Eq. } 9 \\
\text { Ref. } 8\end{array}$ & $\begin{array}{l}0.441 \\
0.456\end{array}$ & $\begin{array}{l}2.200 \\
2.282\end{array}$ & $\begin{array}{l}4.057 \\
4.318\end{array}$ & $\begin{array}{l}0.473 \\
0.488\end{array}$ & $\begin{array}{l}7.805 \\
7.795\end{array}$ & $\begin{array}{l}246.4 \\
225.5\end{array}$ \\
\hline
\end{tabular}




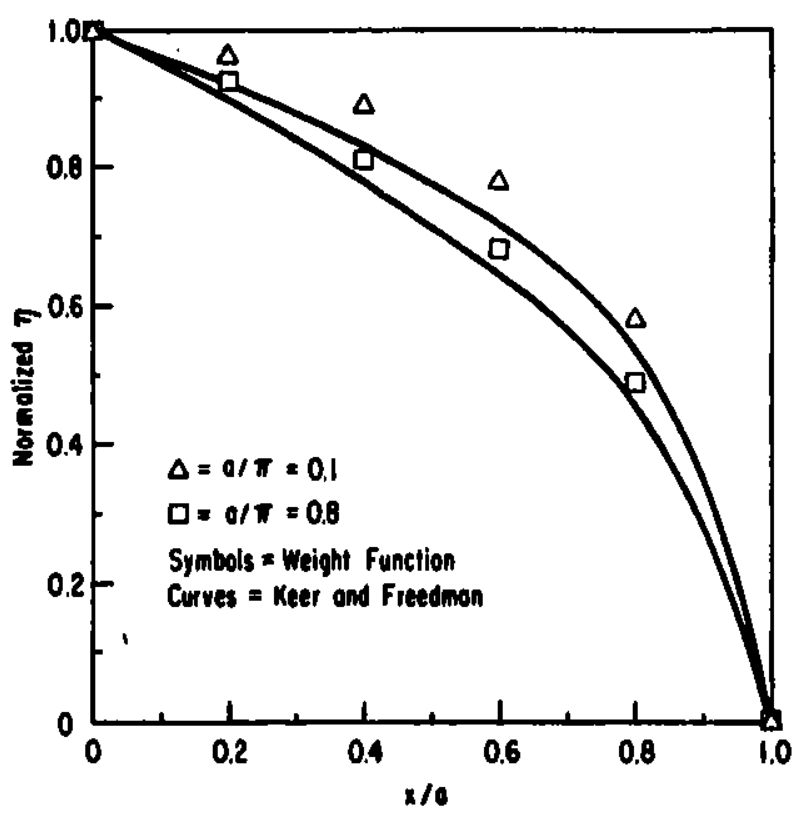

Fig. 4. Crack-opening Displacements Computed from Two-term Representation Compared with Results of Keer and Ereedman's Analysis for the Symmetric Case

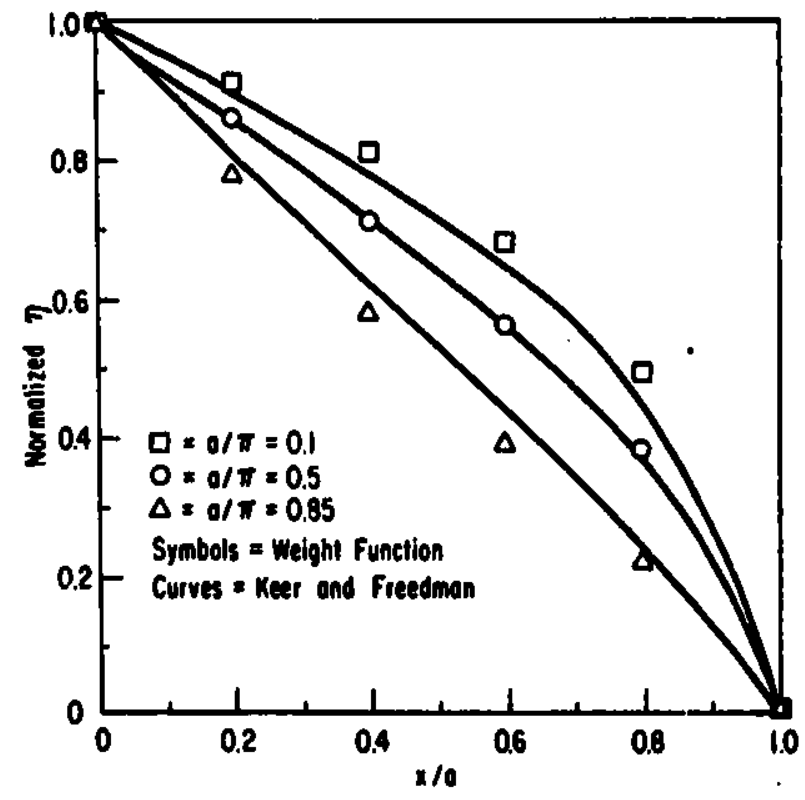

Fig. 5. Crack-opening Displacements Computed from Two-term Representation Compared with Results of Keer and Freedman's Analysts for the Asymmetric Case

\section{RADIAL CRACK FROM A CIRCULAR HOLE}

Bowie ${ }^{5}$ has analyzed radial cracks at the circumference of a circular hole in an infunite plate loaded at infinity, and Grandt ${ }^{3}$ has used the weightfunction formula given by Eq. 1 with Bowie's solution as the reference, supplemented by finite-element computations, to determine calibrations of the 8 tress intensity factor for a variety of practical cracked fastener-hole loadings.

The geometry is shown in Fig. 6. Grandt ${ }^{3}$ has determined a leastsquares approximation to the stress intensity factor of Ref. 5 in the form

$$
F\left(\frac{a}{r}\right)=\frac{F_{1}}{F_{2}+(a / x)}+F_{3}
$$

where, for the single-crack problem shown in Fig. 6 , the constants are

$$
F_{1}=0.8733 ; F_{2}=0.3245 ; F_{3}=0.6762
$$

The radius of the hole, $r$, is used to provide dimensionless length variables.

For a circular hole in an unbounded solid, with uniform tension of magnitude $\sigma_{0}$ at infinity, the distribution of hoop stresses along a radial line making an angle $\theta$ with the loading axis is

$$
\sigma(x)=\frac{\sigma 0}{2}\left\{1+\left(\frac{1}{1+5}\right)^{2}-\left[1+3\left(\frac{1}{1+5}\right)^{4}\right] \cos 2 \theta\right\},
$$


where $\xi=x / x$, with $x$ measured from the circumference of the hole. The stress $\sigma(x)$, which is the stress on the crack faces in the equivalent problem, follows immediately from Eq. 22.

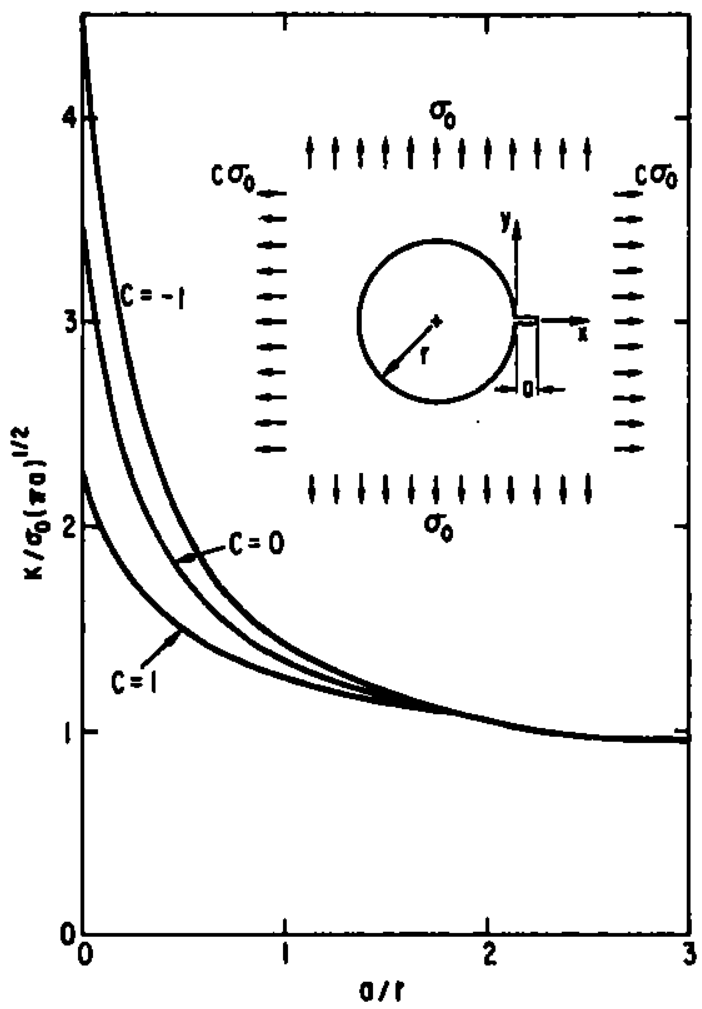

Fig. 6

Stress-intensity-factor Calibrations for a Radial Crack Emanating from a Circular Hole

Equations 20 and 22 may be used to compute the corresponding crackface displacements according to Eqs. 9 and 10. The results can subsequently be used to construct the weight function and to compute stress intensity factors for other loading conditions. Of interest is the case illustrated in Fig. 6, where the remote stress field is biaxial. For this case, $\sigma(x)$ follows from Eq. 22 by adding the results computed for $\sigma_{0}$, at $\theta=\pi / 2$, and $c \sigma_{0}$, at $\theta=0$. For $c=0$, $c=-1$, and $c=+1$, the results are plotted in Fig. 6 . On the scale of the figure, results obtained by Grandt ${ }^{3}$ would be close to those shown here.

Grandt found it necessary to supplement Bowie's results ${ }^{5}$ with a finiteelement analysis to obtain crack-mouth openings, which were then used to construct crack-face displacements using the conical representation of Orange.? The weight function then was constructed, and $K$ was computed according to Eq. 1. Clearly the scheme used here, which is based on the integral identity of Eq. 4 and the approximate representation of Eq. 9, is much simpler.

\section{RADIALLY CRACKED RINGS}

An interesting geometry for the application of the technique of this report is the radially cracked ring. The simplest reference problem is the one 
in which the faces of the $\operatorname{crack}(s)$ are subjected to uniform pressure $\sigma_{0}$. The geometry is shown in Fig. 7. Curves for the stress intensity factors, given in Ref. 4, are reproduced in Fig. 7. This information is sufficient for the construction of the weight function based on the approximate displacement representation of Eq. 9.

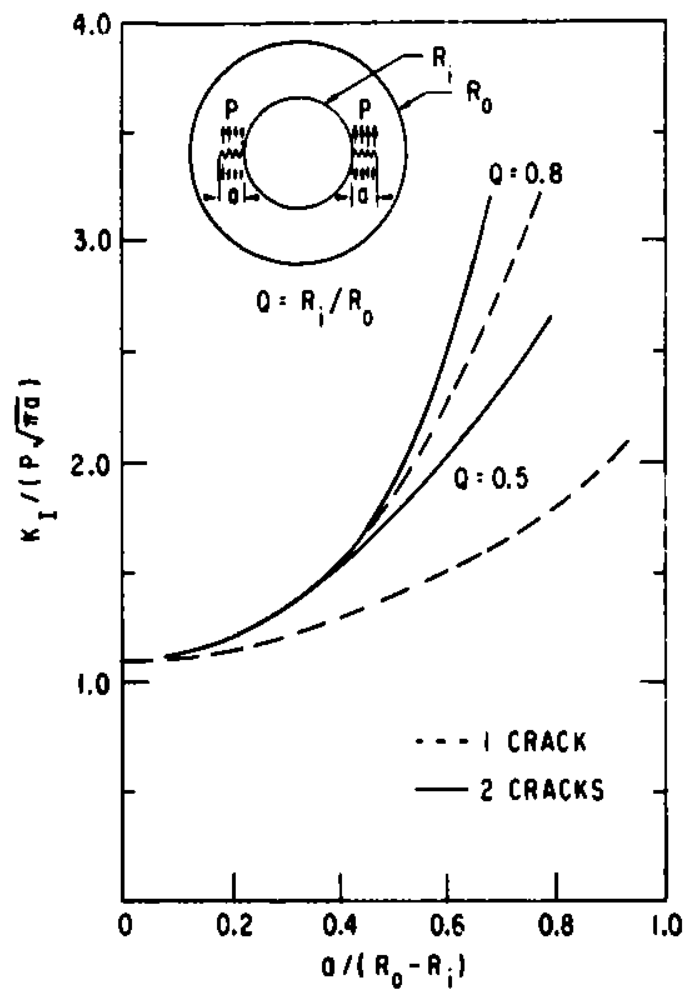

Fig. 7

Stress-intensity-factor Calibrations for Radially Cracked Rings Subject to Uniform Crack-face Pressure (after Grandt)

First we consider the cracked ring subjected to external tension $\sigma_{0}$. The geometry is shown in the insert in Fig. 8. The hoop stress in the uncracked ring is

$$
\sigma(x)=\frac{\sigma_{0}}{1-q^{2}}\left\{1+\left[\frac{q}{q+(1-q) g}\right]^{2}\right\},
$$

where $q=R_{i} / R_{0}$ and $\xi=x /\left(R_{0}-R_{i}\right)$, with $x$ measured from the mouth. Substituting $\sigma(x)$ and the weight function into Eq. 1 leads to the results plotted in Fig. 8. These results compare well with those of Grandt and those of Bowie and Freese ${ }^{12}$ obtained by a modified mapping-collocation technique.

Finally we consider a ring loaded by concentrated forces of $P$ force units per unit thickness. The geometry is shown in Fig. 9. For $R_{\mathfrak{i}} / R_{0}=0.5$, numerical information on the hoop stress in an uncracked ring is given in Ref. 11, and these data were fitted by a polynomial, which was used with the weight function in Eq. 1. The resulting stress intensity factors are shown in Fig. 9, together with analytical and experimental results reported in Ref. 6 and results obtained in Ref. 4 by the weight-function method. 


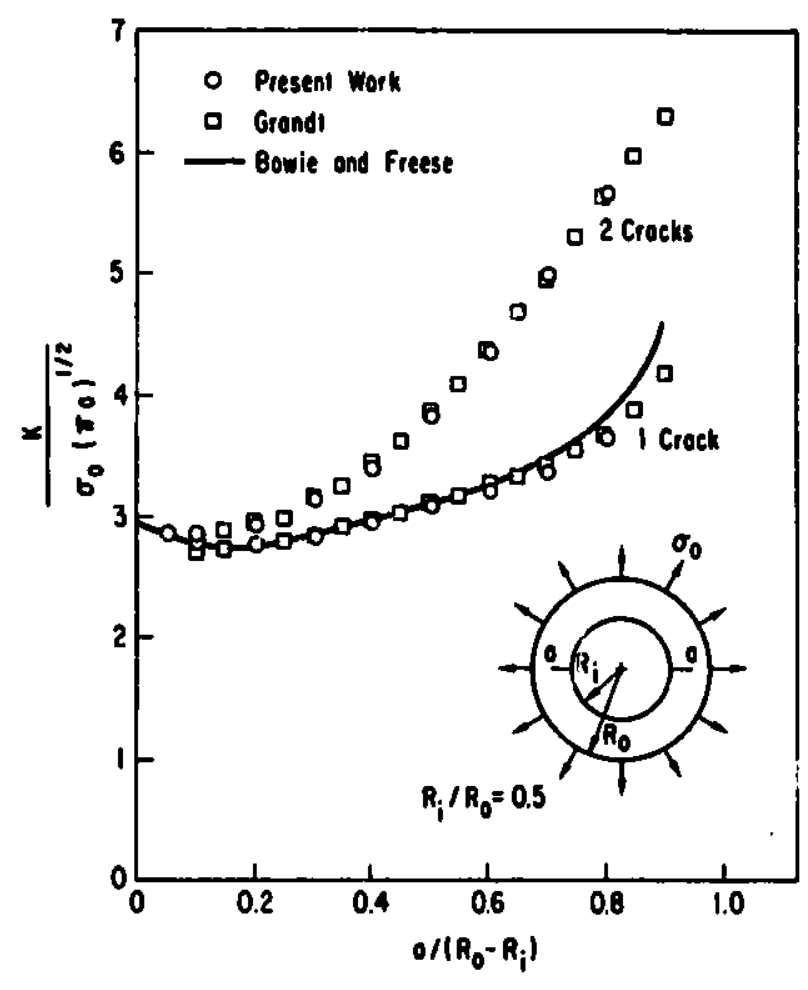

Fig. 8. Comparison of Stress-intensity-factor Calibrations for Radially Cracked Rings under External Tension

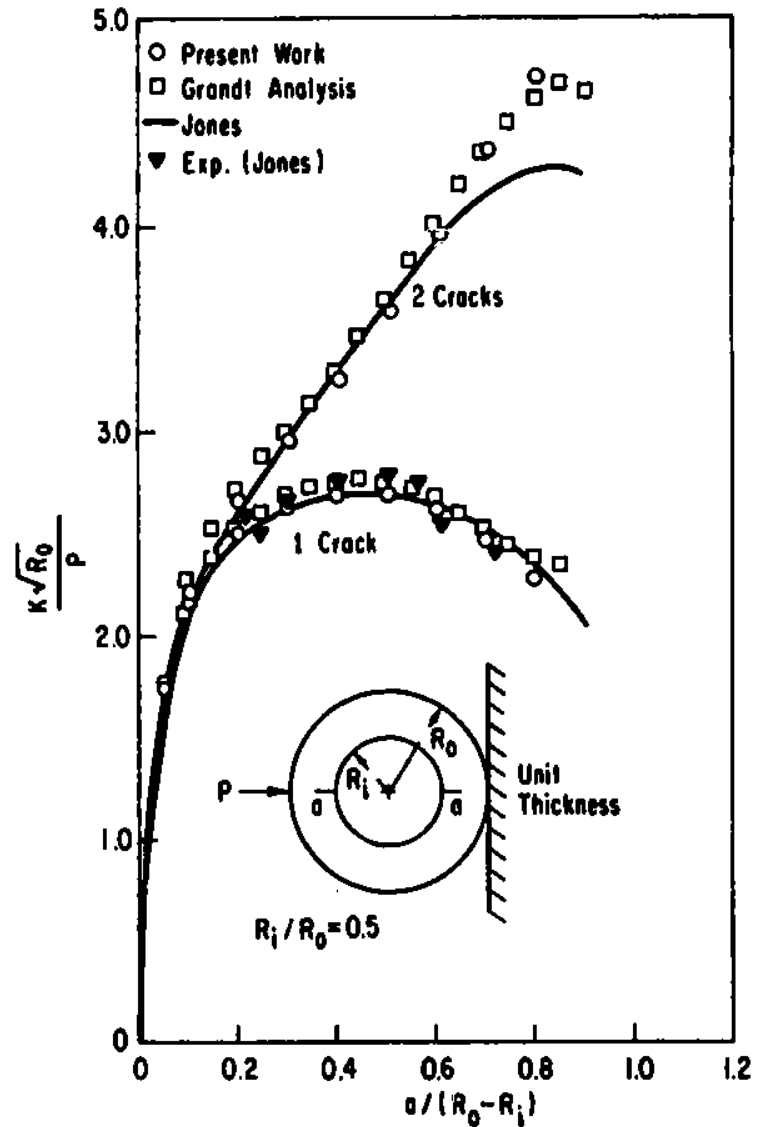

Fig. 9. Comparison of Stress-intensity-factor Calibrations for Radially Cracked Rings Compressed by Concentrated Forces

\section{CORNER-CRACKED HEXCAN}

The hexagonal subassembly ducts found in the cores of advanced nuclearreactor designs are expected to become severely embrittled toward the ends of their lives in the fast-neutron environment. Should scratches, nicks, or other flaws be present in these ducts, also known as hexcans, brittle fracture could result under abnormal loading conditions. A conservative model for such flaws is a long sharp crack, located in an area of stress or strain concentration. Two such cracks are illustrated in Fig. 10 in a hexcan section of axial length $B$. Midflat cracks may be analyzed as cracks in straight beams, for which solutions exist in handbooks. However, the unique geometry of the hexcan corner presents a new problem. Since the corner is such a critical location from a fracture point of view, the determination of a weight function for cracks in that location will provide a powerful tool to perform safety analyses of cracked hexagonal ducts under various loading conditions.

Petroski and Achenbach ${ }^{13}$ established bounds on the plane-strain stress intensity factor associated with a corner crack in a uniformly pressurized hexcan of the dimensions shown in Fig. 11, and a subsequent finite-element analysis 
by Glazik (reported in Ref. 14) provided a $\mathrm{K}$ calibration that fell between the se bounds, as shown in Fig. 12. This latter analysis also suggested that a simple model for the cracked hexcan corner is provided by loading a cracked infinite strip with the stress distribution that exists in an uncracked hexcan corner. Since this stress distribution is readily determined from beam theory, ${ }^{15}$ the stress intensity factors for corner cracks in hexcans loaded in a variety of ways may be estimated with a minimum of computation from the $\mathrm{K}$ calibrations $f(r$ infinite strips that are provided in handbooks such as Ref. 10. However, the weight function based on one $\mathrm{K}$ calibration for a corner crack in a uniformly pressurized hexcan is expected to give more accurate results over a wider range of crack sizes for other hexcan loadings .

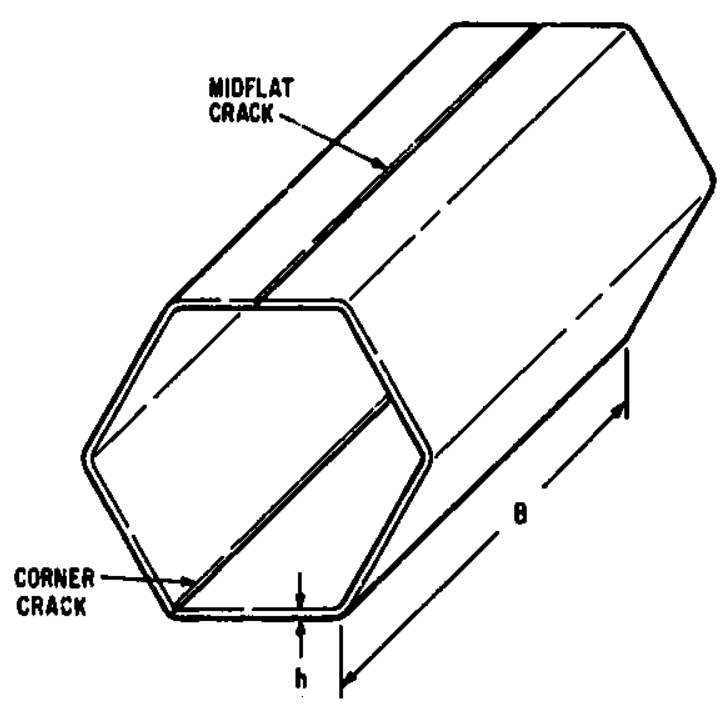

Fig. 10. Cracks in a Hexcan Section

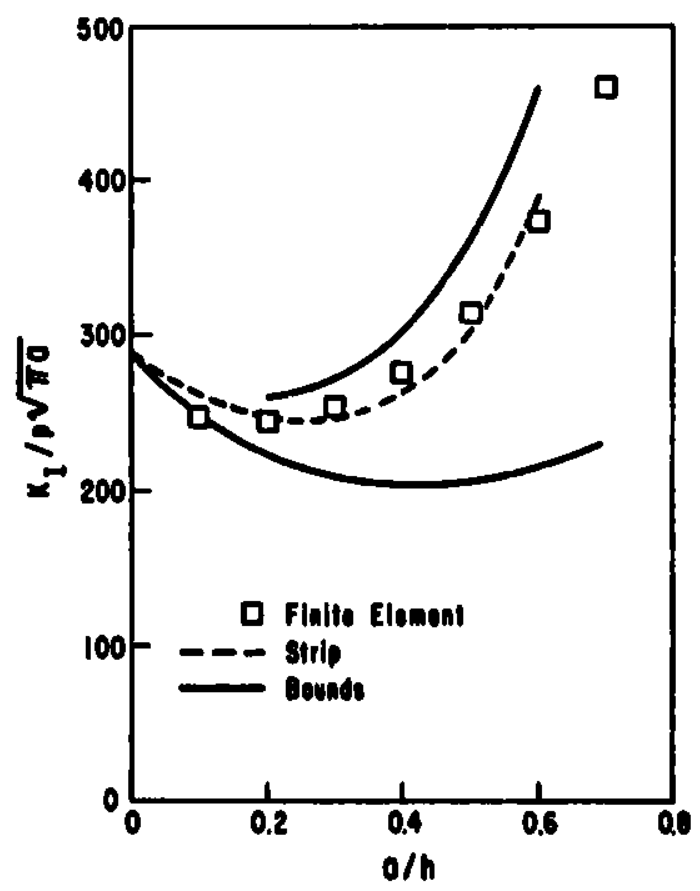

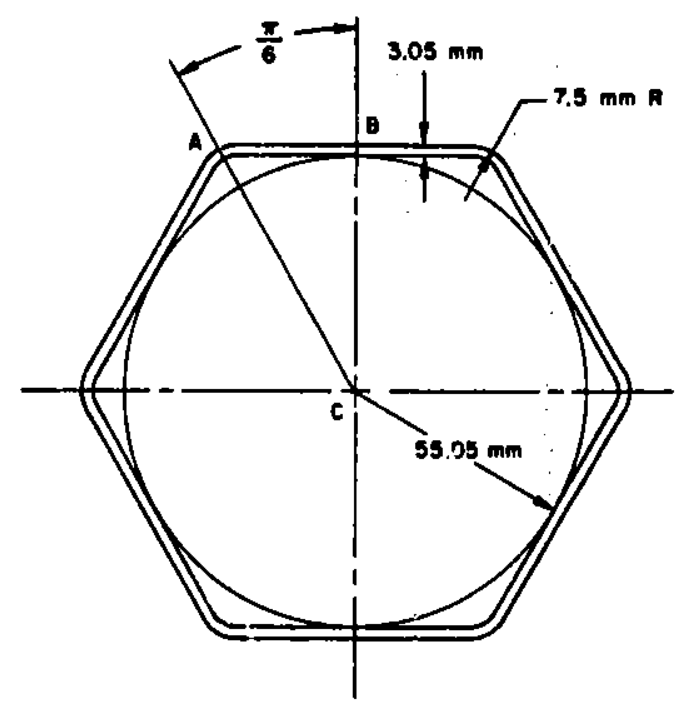

Fig. 11. Dimensions of Hexcan Considered

Fig. 12

Stress Intensity Factors for a Uniformly Pressurized Hexcan with a Corner Crack 
Table III gives the dimensionless stress intensity factor for cracks of various depths in a corner of a uniformly pressurized hexcan. The finiteelement results (from Ref. 14) were fit with a fourth-order polynomial, and the stress distribution through the hexcan corner wall was taken as ${ }^{15}$

$$
\frac{\sigma}{p}=\frac{373.06-730.37 \xi}{1.46+\xi}
$$

where $\xi=x / h$. This information suffices to determine the function $G$ from Eqs. 10-12, and the calculated values of it are also given in Table III. To construct the weight function, polynomials of the form

$$
P=\sum_{m=0}^{5} p_{m}\left(\frac{a}{h}\right)^{m}
$$

were fit in a least-squares sense to the data in Table III. These polynomials were differentiated term by terra to give the derived polynomial expressions

$$
\frac{d P}{d a}=\frac{1}{h} \sum_{m=1}^{5} m p_{m}\left(\frac{a}{h}\right)^{m-1}
$$

for the functions $\mathrm{dF} / \mathrm{da}$ and $\mathrm{dG} / \mathrm{da}$ needed to compute the weight function in Eq. 2 from the representation of Eq. 9.

\begin{tabular}{|c|c|c|}
\hline$a / h$ & $\begin{array}{c}F \\
\text { from Ref. } 14\end{array}$ & $\underset{\text { from Eqs. }}{G}$ \\
\hline 0 & $287^{a}$ & -126.5 \\
\hline 0.1 & 248 & -27.9 \\
\hline 0.2 & 245 & 45.2 \\
\hline 0.3 & 254.3 & 156.8 \\
\hline 0.4 & 276.6 & 339.8 \\
\hline 0.5 & 314.7 & 623.3 \\
\hline 0.6 & 373.8 & 1122.6 \\
\hline 0.7 & 460.4 & 1976.9 \\
\hline
\end{tabular}

TABLE III. Values of the Functions $F$ and $G$ for the Corner-cracked Hexcan Subject to Uniform Pressure

a Limiting value for an edge crack in a half-space, known independent of finite-element analysis.

For a crack of depth $c=a / h$ in a hexcan corner, the explicit formula for calculating the stress intensity factor $K^{(2)}=K^{(2)}(c)$ associated with stress distribution $\sigma^{(2)}=\sigma^{(2)}(\xi)=\sigma^{(2)}(x / h)$ through the hexcan wall is 
$K^{(2)}=\frac{\sqrt{h}}{2 c F \sqrt{2 \pi}}\left[4 c F I_{4}(c)+\left(8 c F^{\prime}+4 F+3 G\right) I_{5}(c)+\left(2 c G^{\prime}-G\right) c^{-1} I_{6}(c)\right]$

where

$$
\begin{aligned}
& I_{4}(c)=\int_{0}^{c} \sigma^{(2)}(\xi)(c-\xi)^{-1 / 2} d \xi \\
& I_{5}(c)=\int_{0}^{c} \sigma^{(2)}(\xi)(c-\xi)^{1 / 2} d \xi
\end{aligned}
$$

and

$$
I_{6}(c)=\int_{0}^{c} \sigma^{(2)}(\xi)(c-\xi)^{3 / 2} d \xi
$$

and where $F^{\prime}=d F / d c=h d F / d a$ and $G^{\prime}=h d G / d a$ are gotten from Eq. 26 and the coefficients in Table IV.

TABLE IV. Polynomial Coefficients for Representations of the Functions $F$ and $G$

\begin{tabular}{ccccccc}
\hline Function & $p_{0}$ & $p_{1}$ & $p_{2}$ & \multicolumn{1}{c}{$p_{3}$} & $p_{4}$ & $p_{5}$ \\
\hline$F$ & 286.4 & -557.7 & 2247.6 & -3204.2 & 2342.8 & 0 \\
$G$ & -126.6 & 1516.2 & -7974.7 & 31677 & -48304 & 33807 \\
\hline
\end{tabular}

The inset to Fig. 13 shows a hexcan loaded by concentrated forces at two opposite midflats. Such a loading mode may be taken as a first approximation to that on a hexcan subject to a jet of fission gas released from a fuel pin that might fail next to an irradiation-embrittled duct. Although the flat opposite the failed pin would be loaded in a more complex way because of the subas sembly internals, the single equivalent reaction force is a reasonable and conservative assumption to represent conditions. In a manner similar to that given in Ref. 15, the stress distribution due to the load $P$ acting on an axial length $B$ of duct may be found to be

$$
\frac{\sigma \mathrm{hB}}{\mathrm{P}}=\frac{46.33-99^{\circ} .35 \xi}{1.46+\xi}
$$

where again $\xi=x / h$.

This stress distribution and the weight function based on the functions $F$ and $G$ were inserted in Eqs. 28 and 27 to give the $K$ calibration for the pointloaded hexcan. These results, hown in Fig. 13, compare very well with 
finite-element results. ${ }^{14}$ Although the infinite-strip model again provides a good estimate, it is not necessaril; conservative for moderate cracks and gives excessively large values for deeper cracks.

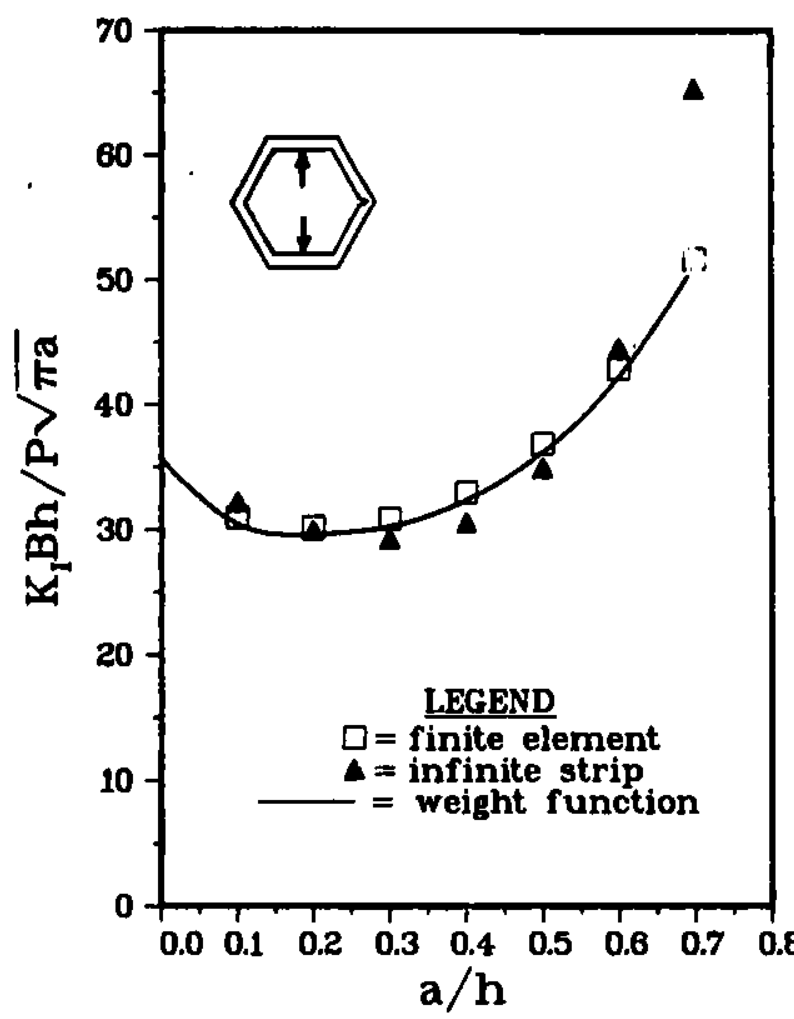

Fig. 13

Comparison of Stress-intensity-factor Calibrations for a Corner-cracked Hexcan Loaded at Opposite Midflats

The weight function constructed here may be used to determine the stress intensity factor $\mathrm{K}$ associated with any other symmetric loading of the corner-cracked hexcan of the dimensions of Fig 11 .

\section{CONCLUSIONS}

The very satisfactory results for the stress intensity factors show the efficacy of the proposed technique to compute the weight function solely on the basis of information about the stress intensity factor for a single reference problem. The principal caveat in applyin's the technique is that one must determine its limitations for extremely deep cracks in a particular application.

The weight function for the corner-cracked hexcan enables one to determine $\mathrm{K}_{\mathrm{I}}$ calibrations for that geometry. Since the use of the weight function involves at most numerical quadrature, it requires only nominal computation time, and many cases may be treated quickly and economically for parametric studies. 


\section{ACKNOWLEDGMENTS}

This work was performed in conjunction with the Argonne National Laboratory Engineering Mechanics Program managed by Dr. S. H. Fistedis. The finite-element results for the hexcan and some preliminary computations for the weight function technique were obtained by Dr. J. L. Glazik. 


\section{REFERENCES}

1. H. F. Bueckner, A Novel Principle for the Computation of Stress Intensity Factors, Z. Angew. Math. Mech. 50, 529 (1970).

2. J. R. Rice, Some Remarks on Elastic Crack-Tip Stress FieZds, Int. J. Solids Struct. 8, 751 (1972).

3. A. F. Grandt, Jr., Stress Intensity Factors for Some Through-cracked Fastener Holes, Int. J. Fract. 11, 238 (1975).

4. A. F. Grandt, Jr., Two-dimensional Stress Intensity Factor Solutions for Radially Cracked Rings, AFML-TR-75-121, Air Force Materlals Laboratory (1975).

5. 0. L. Bowle, Analysis of an Infinite Plate Containing Radial Cracks Originating at the Boundary of an Intermal Circular Hole, J. Math. Phys. 35, 60 (1956).

6. A. T. Jones, A Radially Cracked, Cylindrical Fracture Toughness Specimen, Eng. Fract. Mech. 6, 435 (1974).

7. T. W. Orange, "Crack Shapes and Stress Intensity Factors for Edge-cracked Specimens," Stress Analysis and Growth of Cracks, ASTM STP 513, 71, American Society for Testing and Materials, Philadelphia (1972).

8. L. M. Keer and J. M. Freedman, Tensile Strip with Edge Cracks, Int. J. Eng. Sc1. 11, 1265 (1973).

9. P. C. Paris and G. C. Sth, "Stress Analysis of Cracks," Fracture Toughness Testing and its Applications, ASTM STP 381, 32, American Society for Testing and Materials, Philadelphia (1965).

10. H. Tada, P. C. Paris, and G. R. Irwin, The Stress Analysis of Cracks Handbook, Del Research Corp., Hellertown, Pa. (1973).

11. S. Timoshenko and J. N. Goodier, Theory of Elasticity, McGraw-Hill Book Co. Inc., New York (1951).

12. 0. L. Bowle and C. E. Freese, Elastic Analysis for a Radial Crack in a Circular Ring, Eng. Fract. Mech. 4, 315 (1972).

13. H. J. Petroski and J. D. Achenbach, "Stress Intensity Factors for Corner-" cracked Subassembly Ducts," Proc. Int. Meet. Fast Reactor Safety and Rezi'sd Physic8, Chicago (Oct 5-8, 1976).

14. H. J. Petrosk1, J. L. Glazik, and J. D. Achenbach, "Stress Intensity Pactors for Irradiation-embrittled Hexagonal Subassembly Ducts," Trans. Fourth Int. Conf. Structural Mechanice in Reactor Technology, San Francisco (Aug 15-19, 1977).

15. H. J. Petrosk1, Elastic-Plastic Analysis of Pressurised Ducts with Rounded Corners, Nucl. Tech. 35, 671 (1977).

16. M. I. W1lliams, On the Strese Distribution at the Base of a Stationary Crack, J. App 1. Mech. 24, 109 (1957). 